\title{
REALITY, SYSTEMS AND IMPURE SYSTEMS
}

\author{
J. Nescolarde-Selva \\ Department of Applied Mathematics. University of Alicante. Spain. \\ J.L. Usó-Doménech \\ Department of Mathematics. University of Jaume I. Castelló de la Plana. Spain.
}

\begin{abstract}
Impure systems contain Objects and Subjects: Subjects are human beings. We can distinguish a person as an observer (subjectively outside the system) and that by definition is the Subject himself, and part of the system. In this case he acquires the category of object. Objects (relative beings) are significances, which are the consequence of perceptual beliefs on the part of the Subject about material or energetic objects (absolute beings) with certain characteristics.The IS (Impure System) approach is as follows: Objects are perceptual significances (relative beings) of material or energetic objects (absolute beings). The set of these objects will form an impure set of the first order. The existing relations between these relative objects will be of two classes: transactions of matter and/or energy and inferential relations. Transactions can have alethic modality: necessity, possibility, impossibility and contingency. Ontic existence of possibility entails that inferential relations have Deontic modality: obligation, permission, prohibition, faculty and analogy. We distinguished between theorems (natural laws) and norms (ethical, legislative and customary rules of conduct).
\end{abstract}

KEYWORDS: Connotation, Denotation, Impure sets, Impure systems, Reality, Sign, Significance, Significant, Subject, System.

\section{INTRODUCTION}

A system is a set of interacting or interdependent components forming an integrated whole or a set of elements and relationships which are different from relationships of the set or its elements to other elements or sets.

We distinguish between two classes of systems: abstract and impure systems:

1) A system is abstract when its elements are abstract mathematical entities and relationships are mathematical functions between these elements.

2) A system is impure when its elements are Objects and Subjects:

1) Subjects are the human beings. We can distinguish the subject as observer (subjectively outside the system) and, by definition, is the subject itself, or within the system. In this case, the Subject acquires the category of object.

2) Objects (relative beings) are significances Nescolarde-Selva and UsóDoménech, 2013), which are the consequence of the perceptual beliefs of the Subject of material or energetic objects (absolute beings) with certain characteristics.

The idea that societies and their associate phenomena, such as culture, language, literature, ethic, laws, economics, etc., could more adequately be understood and studied if regarded as systems i.e., as networks of relations that can be hypothesized for a certain set of assumed observables made it possible to hypothesize how the various socio-semiotic aggregates operate. Nevertheless, in spite of common premises, the functional approach has never been quite unified for the reason that, in the General Theory of Systems two different and incompatible interpretations have been circulated: 
1) Theory of static systems (synchronic theory) that has wrongly been identified as the exclusive "functional" or "structural" approach: the system is conceived of as a static or synchronic net of relations, in which the value of each item is a function of the specific relation into which it enters. While the function of elements as well as the rules governing them is thus identified, there is hardly any way to account for change and variation. The factor of time-succession has thus been excluded from the system and ruled to lie beyond the scope of functional hypotheses. Obviously, from the point of view of such an abstract model, the possible concurrent existence of different options within one system at a given moment need not necessarily be considered if these are, in principle, reducible. From the synchronous point of view, the system has a structure of objects and relations. As is well known, it is more efficient from the methodological point of view to start by developing a theory of closed systems.

2) Theory of dynamic systems (diachronic theory): It does not concern the internal structure of the system. The system has two semiotic environments (LloretCliment, Usó-Domènech, Patten, Vives-Maciá, 2002; Patten, 1978, 1982; Nescolarde-Selva, 2010; Usó-Domènech, Mateu, and Patten, 2002; UsóDomènech, Lloret-Climent, Vives-Maciá, Patten, and Sastre-Vazquez, 2002; Usó-Domènech, Stübing, López Vila, and P. Sastre Vázquez, 2002; UsóDomènech and Nescolarde-Selva, 2012): a stimulus (input) environment $\mathbf{H}^{\prime}$ and response (output) environment $\mathbf{H}$ '. The system itself consists of a succession of states with a time interval.

\section{PREVIOUS SEMIOTIC CONCEPTS}

Reality contains interpretable evidence, and the mental ways of communication and their extension, represented in the devices constructed by social man, need to be understood. Beings do not have an intrinsic meaning and are only transformed into signs when we invest them with meaning. The signs are significant units that take the form of words, images, sounds, gestures and objects, studied within a system of semiotic signs, as meaning or code.

Definition 1: The sign is a unit able to transmit representative contents, that is to say, it is a being with denominated significant, that is perceived by the senses, and that in the communicative process carries information for the Subject.

In any process, we can distinguish that it has a significant as an inherent property, and has significance when it is related to the rest of the processes of Reality that the Subject considers as system. (Nescolarde-Selva, 2010; Sastre-Vázquez, Usó-Doménech, , Villacampa, Mateu and Salvador, 1999; Usó-Domènech, Stübing, López-Vila, and Sastre-Vázquez, 2002; Usó-Domènech, Mateu, 2004; Villacampa and Usó-Domènech, 1999; Villacampa-Esteve, Usó-Domènech, Castro-Lopez, and Sastre-Vazquez, 1999; Usó-Domènech and Villacampa, 2001; Usó-Domènech and Nescolarde-Selva, 2012)

Definition 2: The existence of information is independent of the fact that there is a Subject able to decode the message, which it is intended to communicate. This objective information is termed significant (a). 
Definition 3: The information in a message acquires meaning if a Subject decodes the message. This subjective information is termed significance (s).

Therefore, the significant (ם) is an ontic property, considering that the significance (s) will be within of system of meaning. A significant is absolute and infinite, significance is relative and finite. The significant comes from absolute being and significance generates the relative being. The significant is interpreted as the material or physical form of the sign and is something that can be noticed (perception) by some of the traditional senses of the human being. The significance, on the other hand is a mental construct. In our approach, the significant has a truth value equal to 1 , that is to say, $\mathrm{v}(\boldsymbol{\square})=1$ whereas the significance has as truth value a positive real number $v(s)$, between 0 and 1, corresponding to 0 for absolute ignorance of the significant (therefore of the process) and to 1 for absolute understanding, that is to say, $\mathrm{v}(\square)=\mathrm{v}(\mathrm{s})$.

Chandler $(1998,2004)$ insists on a phenomenon that, at least, has two faces: Reality (its perception) is distorted by our systems of signs, but that perception of Reality is not independent of these signs. The sign does not exist without a significant and significance. Within this vision, the significant is considered as the form of the sign and the significance as the content. Eco (1976) affirms that processes can always be given to explain the existence of objects, this is the reason why we assign explanations to codes. Independently of any explanation, a significant will always exist (interpreted as e.g., visual, or verbal signs). On this topic (Chandler, 2004) introduces a philosophical discussion about the role of signs in the construction of Reality. In this sense, modality indicates the status of Reality decided or required by a sign. In semiosis, an interpreter makes judgments of modality about any sign according to his own experience of the world, his environment and his social beliefs in the form in which he constructs his own judgments of modality. Modality as a concept comes from Peirce's model (1992-1998) that introduces the concept of referring to something within the world of experience, with the sign as vehicle.

Definition 4: The semiotic modality is a reference to the truth value of the significance of a sign, distinguishing three alethic categories: present time, necessity and hypothetical possibility.

In agreement with Saussure (1984), signs are organized in codes of two ways: paradigms and syntagmas. These two dimensions are represented as axes in a bidimensional space, where the vertical axis corresponds to paradigm and the horizontal axis represents syntagma (Fig 1).

In a three-dimensional space, the plane of paradigm is one of selection of signs whereas the plane of syntagma corresponds to combination of signs.

Definition 5: The syntagma is an ordered combination of significances, which interact forming a totality with sense, in the form of a chain of elements often ordered in linear form.

These combinations are constructed within a set of rules and syntactic conventions. Syntagmatic relations are the varied forms in which the elements of a system can be related. Significance is syntagmatically related by synchronous form to other significant 
meanings at the same level and constituting their context. Syntagmas are defined as sequential (and therefore temporary). They can also represent space relations.

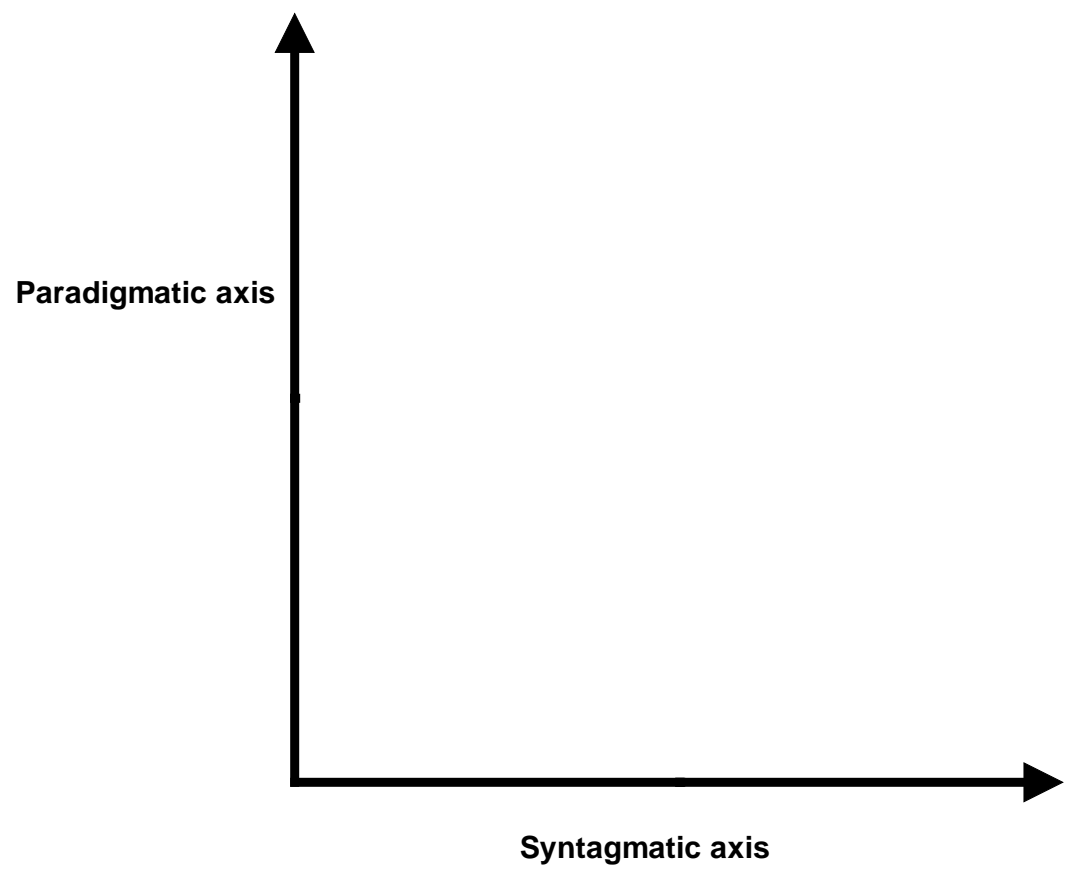

Figure 1. Paradigmatic and Syntagmatic axis

Consequence 1: Syntagmas are created according to the concatenation of significances in paradigmatic sets, chosen according to their property, conventional or required, by means of a determined system of rules, such as grammar.

Consequence 2: In syntagmas, the significance of a syntagmatic unit comes determined by means of its relation with other syntagmatic units. Syntagmas tend to narrow such significances according to the context.

Consequence 3: In a paradigm, significance is determined by difference from other significances, in the sense that the paradigms conceive a possible world plurality.

Consequence 4: Paradigms define and expand Reality, whereas syntagmas contract it.

The significant associated with the sign becomes significance after passing through a filter or sieve, which we will call the doxical filter. This filter consists of two essential components: the language and the belief system.

Language is in the origin of the systemic conception of Reality. Language may be defined as a symbolic substitute of Reality, or as a system of signs. Different classes of objects exist, that are characterized by different mental acts through which we distinguish them from their surroundings (Meinong, 1904). Objects of sensorial perception are different from objects of thought, but these latter ones are not less "objective" than the previous ones: they are apprehended through thought but it does not constitute them. According to the terminology of Meinong, meaning subsists, whereas individual beings and qualities exist. In this sense, objects of thought can be real without existing in the technical sense defined by Meinong. Mathematical objects 
are of this class. The first condition is that these objects are there, and this does not happen through an act of discourse, but through the presence of these objects in the Subject's thought (Agazzi, 1992). The phenomenological situation is perhaps that an object, simply by the fact of being present, offers to the Subject an irrefutable and particular witness of itself. The referential situation is the phenomenological presence of the object. And the truth of a sentence is the coincidence between the situation and its phenomenological presence. It is to notice that meanings or understandings are only partially faithful with respect to any particular phenomenological presence or referential situation that they could denote. Some form of modalization (alethical, Deontical or doxical) necessarily accompanies the communication. There is a clear epistemological separation between thought and language. All organization of a language depends on a complex structure. Biunivocal correspondence between the perception of Reality and the linguistic system is unthinkable. One operates from a superior order, from a mesosystem that would include them and in where both appear as elements and not as closed and independent units. Horizontal forces of all systems are those that determine their potential of significance. This means that no language is neutral, and that any representational space is not neutral either. That is to say, the systemic conception, as any other semiotic conception, represents Reality in the same way as other nonsystemic conceptions. By virtue of what we have just written we can propose the following principle:

Semantic Incompleteness Principle (Nescolarde-Selva. 2010; Usó-Domènech and Nescolarde-Selva. 2012; Nescolarde-Selva and Usó-Domènech. 2013): It is not possible to totally characterize a structure of objects or processes with a language (formal or not), or to completely present a portion of "truth" that this language can express about these objects or processes through its deductive operation.

\section{Consequences:}

1) There is an inadequacy of the semantic dimension relative to the benchmark of the phenomenological situation.

2) There is a mismatch between the semantic dimension and the phenomenological situation in relation to syntactical semantics.

This Semantic Incompleteness Principle is a consequence of Gödel's famous theorem (1931) and the Nonwished Effects Theorem (NWET Theorem) (Nescolarde-Selva, 2010; Usó-Domènech and Nescolarde-Selva, 2012).

Language is relative as well. How can we speak about absolute being, then? We can and we cannot. We cannot completely speak about it, but this is not a reason to stop speaking about it (Wittgenstein, 1972), because we can incompletely represent its completeness. We would not be able to speak about anything, because languages are incomplete. Language is used inside a context. Depending of this context the language will be different.

Reason cannot prove the beliefs it is based upon. Beliefs arise through experience. Nevertheless, experience needs previous beliefs and reason to be assimilated, and reason needs experience to be formed, and beliefs need reason as well. Beliefs, reason and experience are based upon each other. Context is dynamic, and formed upon beliefs, reason and experience. This is where relative being lies. Since the relative being is dependent on our context, it is also dependent on our beliefs, reasoning, and 
experiences. Contexts are dynamic because they are changing constantly as we have new experiences; we change our beliefs, and our ways of reasoning.

Definition 6: Belief systems F (Borhek, \& Curtis1983) are structures of norms that are interrelated and that vary mainly in the degree to which they are systematic. What is systematic in the Belief system is the interrelation between the several beliefs.

Perceived Reality is constructed by means of systems of signs, being affected and being changed by means of Belief systems. Peirce (1992-1998) demonstrates that the semiotic process has been half-full culturally, that is to say, within a certain Belief system a Subject cannot understand a sign without talking about a socially learned system that filters his perception. In the same way, the classification of signs in closed typologies can be deceptive, since the status of the sign depends strongly on the form in which the sign is used within any Belief system. A sign can nevertheless be iconic in one belief context and be symbolic in another context.

Consequence 5: Signs cannot be classified in terms of categories without reference to the intentions of the Subject within individual belief contexts (Chandler, 1998).

Consequence 6: Any sign within the semiotic process is not a monolithic and arbitrary thing, but one that is open to the uses and interpretations within a language $L$ and of a Belief system B (Eco, 1973; Chandler, 1998).

Definition 7: A concept is a set of inherent properties of the perception (significant) of a communicating person, that is interpreted with significance, registers similarities and differences on which the classes and classifications are based, and that within the natural language appears in, for example, names, adjectives and intransitive verbs.

However, it is semantics that give rise to the concept rather than the interpretation of the representation. The interpretation derives from the person's Epistemology or belief system or ideology.

Definition 8: The Semiotic Environment is the environment formed by the epistemologies and associated Belief systems surrounding the Subject.

If the semiotic environment determines the content or message, then the distinction between form and content is problematic, introducing the idea that both expression (significant) and content (significance) equally have substance and form.

Example 1: We think it was Hesiod who said "The sun shines equally in Persia and Hellas, but the concept of good and evil are different."

\section{PERCEPTUAL BELIEFS}

Gershenson (2001) defines two types of being: absolute being and relative being. The first one is independent of the observer $S$ and infinite. Relative being is dependent on the Subject, therefore finite, and different in each individual. Absolute being should not be confused with materialism. Materialism is relative, and we cannot say for sure if beings are absolutely materialistic or not, because we do not know what matter is absolute. A Subject can only speculate about what things are absolute, he cannot be absolutely sure, he can only speculate, because things are absolutely infinite and the Subject is not. The Subject cannot say that something is absolutely true or false. He can 
only assert beings in a relative way and he could assign truth values or vectors to them, but these would be relative to his context. The being would be the conjunction of relative being and absolute being, with the corresponding confusion derived from the need to define and to speak about something that is absolute and relative, infinite and finite at the same time. That is what we do every day. Beings do not have an intrinsic meaning and they only transform themselves into signs when we invest them with meaning.

Consequence 7: A linguistic sign is not only an element that enters the communication process, but it is an organization of the meaning process.

The significance of a linguistic sign also depends on the code in which it is located, since the codes give a scheme, amalgamated also with belief conventions, within which the linguistic sign acquires sense. This allows text interpretation (systems) organized in agreement with codes and subcodes reflecting values, attitudes, beliefs, assumptions and practices. This implies a certain stability in the relations between significant and significance, restricting the amount of possible interpretations (Nescolarde-Selva, 2010; Nescolarde-Selva and Usó-Domènech, 2013; Usó-Domènech and Nescolarde-Selva, 2012) .

Definition 9: The denotation (d-s) is the literal, obvious definition or the common sense of the significance of a sign.

Definition 10: The connotation (c-s) is the socio-cultural and individual associations, the ideologies derived from the belief systems, and the emotional meanings belonging to the psychology of the Subject, that are the indirect function of the Semiotic Environment (context) in which is immersed.

Both distinctions involve the use of learned codes. The significance tends to be multiplied from an individual sign, until it is equipped with many meanings that go beyond what the sign says. Different orders of meaning or levels of significance exist:

1) The first order of significance is the denotation, at which level there exists a sign t consisting of significant and significance.

2) The connotation is a significance of the second order that uses the denotative sign (with significant and significance) as its significant, with an additional associate significance.

This distinction considers the connotation as a sign that is derived from the significant of a denotative sign, so that the denotation takes us to a chain of connotations. Denotation is an underlying and primary significance.

Consequence 8: The significant (ם) or significance s depends entirely on the level in which it operates in the analysis. Then, significance is a level of the context; it can be the significant at another level.

The subject receives two types of semiotic stimuli:

a) Significant from the person's own processes or being. 
b) The significant of the transmitted semiotic stimulus or the significant of the significance (connotation).

This fact requires us to distinguish two types of significant:

Definition 11: The A-significant (A- $ם$ ) or the first order significant is the significant that is inherent to beings, processes or phenomena of the referring context.

Definition 12: The B-significant (B-ם ), the second order significant or connotation, is the significant of significance $s$.

Connotation B- $ם$ has a truth value v'(B- 1 ) = 1 having simultaneously, a relative truth value or connotative truth value $v(s) \in[0,1]$. That is to say, we received solar light rays with significant $S$ and a significance $s$ of the light, Sun, etc, concepts with a truth value $v(s) \in[0,1]$, having relative significant (B- $\mathbf{B}$ ) with a truth value v'(B-ם)=1.

Consequence 9: Changes in the form of the significant can generate different connotations.

Let $\mathrm{F}$ be a Belief system and $\mathrm{L}$ be a language each forming a doxical filter.

Definition 13: Each significance $s$ is function of the components of a doxical filter, that is to say, the Belief system and its associated language, so that $s=f(F, L)$. This function $f$ we will call the significance function.

Consequence 10: The definition of the connotation(c-s) of a sign is the set of possible senses or significances, depending on contexts and Subjects.

Consequence 11: The denotation is the most stable and apparently verifiable of the connotations.

Consequence 12: If the Subject interprets the sign as something that interposes, we can affirm that the sign always has a connotation, and denotation is only the dominant connotation, being interpreted as the true meaning of a being, process or text.

Consequence 13: The relative truth value of denotation or the denotative truth value will be v'(B- ) =1.

Consequence 14: All the B-significants included in the conceptual space of the perception of Reality (context), will be denotative, therefore, they will have for the Subject a denotative truth value equal to 1.

We are going to call $s$ the systemic significance, that is a denotative significance. We will call $\zeta$ the set of significant (signs) of Reality and $\zeta_{\Sigma}$ the set of systemic significants, that is to say, the set of signs that have been limited by the Subject when establishing the borders of the system, and so that $\zeta_{\Sigma} \subset \zeta$. 
Definition 14: The denotative systemic significance (d-significance) $s_{\Sigma}$ if it is a function defined in $\xi$ so that if $\xi_{\Sigma} \subset \xi$ then $s_{\Sigma}\left(\xi_{\Sigma}\right) \subseteq \xi_{\Sigma}$

Note 1: The denotative systemic significance (d-s) is the significance of the absolute beings.

Note 2: The concept of denotative systemic significance ( $d$-s) coincides with the concept of relative beings.

Let $\mathrm{S}$ be a subject, and $\mathrm{O}$ an object under specified conditions. Maddy's conditions (Maddy, 1990, 1996) for physical perceptions are the following:

The $\mathrm{S}$ perceives $\mathrm{O}$ if:

1) O exists. It is the absolute being.

2) $\mathrm{S}$ has perceptual beliefs $\mathrm{pB}$ about $\mathrm{O}$, in terms of appropriate sorts of concepts. Rather than talking about belief in a physical object, one talks about the concept of a physical object or of a relative being. This is based on the assumption that having a concept of a physical object entails that one has a belief in physical objects.

3) S’s beliefs B about $\mathrm{O}$ are caused by S's experience of $\mathrm{O}$.

Definition 15: The significances, that are the consequence of the perceptual beliefs $p B$ of the Subject $S$ about an object $O$ with certain characteristics $C$, we call perceptual significances (p-s) and we will denote it as ps.

\section{THE SYSTEMIC CONCEPTION OF REALITY}

We assume the existence of an Absolute Reality, unattainable by human knowledge, that is not fragmented into parts. This Absolute Reality we denote as $\mathbf{\aleph}$. We suppose also that there is a relative reality, achievable by human knowledge, that is fragmented into parts. This relative reality is denoted as $ב$ and will be considered by the subject $S$ as the only Reality. Let $\mathrm{K}$ be the operator of knowledge that is part of the subject $\mathrm{S}$. Subject S is conceiving Reality $ב$ through his doxical filter made up of the own beliefs system $\mp$ of his culture, and by a certain language L. Subject $S$ is in a certain psychic state of organization of Reality during a determined objective temporary interval $\left[t_{0}, t_{n}\right]$. Then:

Hypothesis 1: $\Rightarrow \exists \beth \backslash S \in \beth . \neg K \aleph （ \aleph \Rightarrow \exists \beth)$ and $\mathrm{K \beth} \neg(\Rightarrow) \mathrm{K}$

Hypothesis 2 (Condition of rationality): A subject $S$ is rational if he fulfills some conditions to be described as rational. $S$ is rational if he knows the laws of logic. If $K P_{1} \wedge K\left(P_{1} \rightarrow P_{2}\right) \mapsto K P_{2}$.

Hypothesis 3 (Subjective condition): The conception on the part of $S$ of the ב will depend on the conception that $S$ has of himself within the Reality ב which includes this Subject. 
Omphalical Belief condition: from the Greek language "omphalos" (o $\mu \varphi \alpha \lambda o \varsigma)$, the axis mundi is a symbol representing the point of connection between sky and earth. This places it at the center of the world: at its omphalos (navel) the world's point of beginning. Reality ב has not an objective center. Nevertheless, Subject $S$ is the subjective center of everything surrounding him - of Reality ב. He is the omphalos.

Janus Belief condition: Subject $S$ thinks that Reality $ב$ is outside him. He is part of the Reality and at its center and simultaneously he is separated from it. He thinks (he believes) about the existence of environment according to the conception of the Cartesian dualism: "I and my environment". He looks inwards inside (himself), and outwards (environment).

Hypothesis 4: The concepts of system $\Sigma$ are abstract mental constructions with an organisational concept of Reality ב conceived by the Subject, by means of a perception (own or amplified) and ratiocination, through significances extracted from Reality and expressed by means of a specific language $L$.

Hypothesis 5: The system $\Sigma$ is an organization of knowledge on the part of the subject $S$ that fulfils the following conditions:

a) The subjective condition.

b) The condition of rationality.

c) The external condition.

d) S knows what a system is.

Hypothesis 6 (External condition): The behavior of the system $\Sigma(ב)$ is determined by the Belief system $F$ that subject $S$ conceiving this system assumes as true, about himself, the conceived system and its environment.

Let us suppose that we have a set $\Gamma$ formed by subject $N$ that $\Gamma=\left\{S_{1}, S_{2}, \ldots, S_{N}\right\}$ is located "inside" the system as observable and a Subject $\mathrm{S}$ located "outside" as observer. We will have a set formed by $\mathrm{N}$ operators of knowledge $K_{1}, K_{2}, \ldots, K_{N}$, one for each subject. An expression $K_{1} P_{1}$ can be read as Subject $S_{1}$ knows $P_{1}$. Then $K_{1} K_{2} P_{1}$ can be read as $S_{1}$ knows that $S_{2}$ knows $P_{1} . \quad K_{1} P_{1} \wedge K_{1}\left(P_{1} \rightarrow P_{2}\right) \rightarrow K_{1} P_{2}$ can be interpreted as if $S_{1}$ knows $P_{1}$ and knows that $P_{1} \rightarrow P_{2}$, then he knows $P_{2}$.

Hypothesis 7 (Internal condition): The vision of a system $\Sigma(\beth)$ interpreted by the set formed by different subjects $\Gamma$ inside the system is determined by the Belief system $F$ that the said subjects or their majority conceive as true, about themselves, of the system and about its environment.

Let $\Sigma(ב)$ be the concept that $ב$ is a system. We shall refer to the knowledge operator as $\mathrm{K}$ and the belief operator as B. Therefore we may say with (Halpern, 1985):

1) If $S$ knows that $ב \rightarrow \Sigma(ב)$ and also knows that $ב$, then he should also know that $\Sigma(\beth): \mathrm{K}(\beth \rightarrow \Sigma(\beth)) \rightarrow(\mathrm{K} \beth \rightarrow \mathrm{K} \Sigma(\beth))$.

2) S only knows what is true: $\mathrm{K} \Sigma(\beth) \rightarrow \Sigma(\beth)$.

3) If S knows $\Sigma(\beth)$, he knows that he knows: $\mathrm{K} \Sigma(\beth) \rightarrow \operatorname{KK} \Sigma(\beth)$. 
4) Rule of necessarily $[\mathrm{K}(\beth \rightarrow \Sigma(\beth)) \rightarrow(\mathrm{K} \beth \rightarrow \mathrm{K} \Sigma(\beth))] \wedge[\mathrm{K} \Sigma(\beth) \rightarrow \Sigma(\beth)] \wedge[\mathrm{K}$ $\Sigma(\beth) \rightarrow \mathrm{KK} \Sigma(\beth)]$.

5) Rule of non-monotonicity: If for a subject S, with $\Sigma(\beth)$ and $\mp$, does not belong to the Belief system $\Sigma(\beth) \notin \mathrm{F}$, then $\urcorner \mathrm{K} \Sigma(\beth) \in \mathrm{F}$, and we can state that $\mathrm{F}$ is a Stable Belief System.

Then for a subject S, we may establish the following axioms:
a) Axiom 1: $K \Sigma(\beth) \rightarrow \Sigma(\beth)$.
b) Axiom 2: B $\Sigma(\beth) \rightarrow K \Sigma(\beth)$.
c) Axiom 3: B $\Sigma(\beth) \rightarrow \Sigma(\beth)$.
d) Axiom 4: K $\Sigma(\beth) \rightarrow K K \Sigma(\beth)$.
e) Axiom 5: B $\Sigma(\beth) \rightarrow K B \Sigma(\beth)$.
f) Axiom 6: $K \Sigma(\beth) \rightarrow B \Sigma(\beth)$.
g) Axiom 7: ${ }_{\urcorner} \mathrm{B} \Sigma(\beth) \rightarrow K_{\urcorner} \Sigma(\beth)$.
h) Axiom 8: $\urcorner B_{\urcorner} \mathrm{K} \Sigma(\beth) \rightarrow \mathrm{K} \Sigma(\beth)$.
i) Axiom 9: $\rceil K \Sigma(\beth) \rightarrow B_{\rceil} \Sigma(\beth)$.
j) Axiom 10: $\mathrm{K}_{\urcorner} \Sigma(\beth) \rightarrow \mathrm{B} \Sigma(\beth)$.

Hypothesis 8: Subject $S$ has so many relations with reality he that cannot extract from them a key to include them all.

The absolute truth of the representations cannot be established, but it is possible to be shown whether a given proposition is represented as true or not. The truth is constructed from semiosis, and as such it is the truth of a particular social group, within a Semiotic Environment, rising from values and beliefs of that group.

Consequence 15: Reality ב has many interpreters and therefore multiple subjective realities exist, that are the product of definitions given by the Belief systems, and as such, they are not equal in status. Realities confront each other, and are in opposition.

LeShan and Margenau (1982) propose that the organization of knowledge divides Reality in experience domains and in each one of them certain observable phenomena are expressed. Some domains have a direct relation with each other and when this happens it is possible to make a series of formulations defined by their relations. When the domains are related to others according to scales of dimensions of complexity usually we can say that they form a hierarchy. In these conditions, the observable phenomena in one domain cannot be conceived nor be predicted generally from another domain. But if two domains are considered to be in opposed directions, we verified that the observable phenomena in the second domain can be explained taking care of the phenomena of the first domain. According to these authors, an important general law concerning domains is the following: the observable phenomena that appear in any domain legitimately are related to each other between themselves. In accordance with the present state of knowledge and science, no domain of experience is more real than another one. Each one has the same worth as another one. "Nature has neither rind nor bone", said Goethe. We chose a domain according to the sights that we have. Even though the domains are related in a hierarchy none of them is more real than the other.

The domains enter groupings called spheres and each sphere has one special organization of reality (its Metaphysical system) that is necessary so that the data of that sphere are valid. LeShan and Margenau divide the spheres of experience into five: 
a) Sphere of things too small to be seen or touched at least theoretically: the Microcosm. It is the field of Quantum Mechanics.

b) Sphere of the tactile line of vision and up to the limits of instrumentation. It could be called also the sensory sphere or average existence.

c) Sphere of very large objects or things that theoretically happen too fast to be seen or to be touched: Macrocosms. It is the field of relativistic Physics.

d) Units of conduct with sensory feedback: conduct units that depend on reflections.

e) The sphere of inner human experience, including bodily sensations.

The three first spheres are those in which the natural scientists apply their methods. A unique rationality does not exist either that governs the entire universe, all ofReality.

Hypothesis 9: The essence of the organization of Reality $ב$ is that the data of each sphere of experience must be taken on its own terms without preconceptions. What can differ in each sphere of experience are not only observables and the their relations, not only the definitions of space, time, state and observer, but also the methods to study each domain.

In the sphere of conduct units we could establish several different subspheres :

a) Subsphere of strictly biological things.

b) Subsphere of ecological relations (collective).

c) Subsphere of human conduct with sense or molar conduct and its own momentum.

d) Subsphere of human collective molar conduct (social conduct).

In subspheres $b$ and $d$, the possibility of prediction through statistical mathematical models exists, but that only indicates the probability of a tendency and certainty about the direction of the tendency does not exist.

Definition 16: A system with concepts is a semiotic system when representations and functions form pairs. The function is determined by semantic properties (significance) within the physical restrictions (significant).

Note 3: The constituent elements of a system are symbols. From this, it is deduced that a system is not more than a symbolic representation of Reality.

Note 4: Any system is, by definition, a semiotic system, since in its interpretation of Reality it cannot do without concepts.

\section{IMPURE SETS AND IMPURE SYSTEMS}


Mathematical models are used to study the subspheres a, b and d. These models are based on the Theory of systems. The systems to be modeled are what we have defined as impure systems, being its elements materials and / or energy entities. Let's delve into these concepts.

Sets of Objects will form an impure set of the first order;

1) An impure set is one whose referential elements (absolute beings) are not counted as abstract objects and has the following conditions: They are real (material or energetic absolute beings).

2) They exist independently of Subject.

3) A subject develops perceptual significances on them.

4) True things can be said about them.

5) A subject can know these true things about them.

6) They have properties that support a robust notion of mathematical truth.

7) The systems of interest are called Deontical Impure Systems (DIS) to emphasize their essential characteristics.

A set is a mathematical object. We can to establish three possible theses (Benacerraf, 1973; Maddy (1990, 1996):

1) Knowledge of mathematical objects requires a causal relation between these objects and Subject. This is taken to be a consequence of the causal theory of knowledge.

2) On the Platonist's account there can be no causal relations between mathematical objects and other entities. There are results from the characterization of mathematical objects as abstract.

3) Subject $\mathrm{S}$ knows some mathematics.

Mathematical perception is as similar as possible to physical perception.

Definition 17: The impure sets (Maddy, 1990) are sets whose referential elements (absolute beings) are not counted as abstract objects and have the following conditions:

a) They are real (material or energetic absolute beings).

b) They exist independently of the Subject.

c) $S$ develops p-significances on them.

d) True things can be said about them.

e) Subject can know these true things about them.

f) They have properties that support a robust notion of mathematical truth.

Maddy considers two main lines of objection: 
1) There are not states in the Platonic sense of real objects, separate from the activity of a Subject. This objection is countered by appealing to Quine\&Putnam type indispensability arguments (Quine, 1969): there is no way to account for the practice and utility of mathematics other than through assuming the existence of some mathematical objects, and these will generally include sets. The only strong arguments against these indispensability claims are Field-type proposals for nominalizing mathematics (Field, 1980, 1989).

2) Even if it is granted that sets exist, if does not follow that the Subject perceives a set rather than some other sort of physical or abstract object. The subject's perception involves, among other things, a numerical belief $n B$ (Booth, R., 2002). Objections concern the bearer of this numerical property about which Subject has his belief. The first proposal is that the physical stuff has the numerical property but Frege's objection to this: the physical stuff has no determinate numerical properties.

3) There exist four options, for something that divides up the physical stuff (MacCallum, 2000):

a) Sets exist.

b) The Aggregate: Some would say, the objects, meaning by this the physical stuff divided up by the property of being an object.

c) The concept: A numerical statement is a statement about a concept.

d) The class: what is usually called the class of objects.

Sets, aggregates, concepts and classes require numerical properties. Subject S perceives a set not because he perceives that it is a set, but because he perceives something that bears numerical and mathematical properties and his theoretical concerns, based on Quine/Putman arguments, tell him that this bearer of the mathematical properties is a set.

Let $\Psi$ be a mathematical object, (i.e. an impure set of rank one) under same specified conditions. Previous arguments concerning the bearer of the numerical property have established this:

1) Condition 1: is that there be an impure set in front of $S$.

2) Condition 2: is that $S$ has a perceptual belief about the impure set in front of him. It is not necessary that $S$ perceive that the bearer of any numerical property is a set, only that theoretical considerations tell him that the object of his belief is a set. S may not know that it is a set he is perceiving even if he has $p B s$ concerning the set.

3) Condition 3: $\Psi$ causes $S$ 's nBs about $\Psi$. This establishes the necessary link between causal interaction and perception. Following Maddy (1990), the mathematical concept $(\mathrm{nB})$ of a set is as independent of language as the physical concept of object; both are formed prior to acquisition of the relevant linguistic abilities. 
Definition 18: The s-impure sets are sets formed by the p-significances of impure sets, that act as references in the Subject's mind, by means of numerical and perceptual beliefs.

Note 5: P-significances are d-significances of objects pertaining to impure sets.

Definition 19: The second order s-impure set is the set whose elements are s-impure sets.

Systemic philosophy asks the question, "How can we understand systems?" We look at the world in terms of facts and events in the context of wholes, and we understand them as integrated sets purposefully arranged in systemic relations. Systemic relations express (for subject S) causality within the system. Three essential types of causality exist, the relation cause-effect, relation effect-cause and, finally, inferential relation. As Beaugrande and Dressler say (1997), the "relations of causality regulate the way in which a situation or an event influences the conditions where they occur so another event happens". Relational determination is causal and causal connections are of two classes: transactions and relations.

Definition 20: A binary transaction is direct exchange of energy and matter between two absolute beings.

Binary transactions have the following properties:

1) Transactions are ontic or "real" categories.

2) Transactions have priority in model formulation since they imply transferences of matter or forces between absolute beings without which relations could not be defined.

3) Nevertheless, given an established ontic dominion, relations can initiate and condition transactions and in this sense are high-priority.

Definition 21: A binary relation is an indirect consequence of these direct exchanges, extended to two or more absolute beings in a certain time interval $\left[t_{0}, t_{f}\right]$.

Binary relations have the following properties:

1) Relations are epistemic or "virtual" categories, implicit in transactions.

2) It is impossible to define which is first in a system: transactions or relations.

Definition 22: Inferential interactions are defined by how the transactions or relations between relative beings whose p-significance is informational, extending physical matter and forces that underlie their absolute beings.

For our approach, we shall use the hypothesis of system linkage, developed by LloretCliment, et al. (1998). 
Definition 23: A semiotic system is a system whose set object $M$ is formed by the significance of ontological entities or relative beings and whose relational set $R_{I}$ is formed by inferential relations.

Consequence 16: Every system formulated by the Subject $S$ is a semiotic system.

Consequence 17: Semiotic systems are oriented, causal and functional systems defined by a Subject considered external (by the Omphalical and Janus conditions) and whose object set responds to information.

Definition 24: A simple impure system-linkage $\Sigma \equiv(M, R)$ is a semiotic system consisting of the pair formed by an impure object set $M$ the elements of which are $p$ significances (relative beings) of entities belonging to Reality (absolute beings) or certain attributes of these, and a set of binary relations, such that $R \subset P(M \times M)=$ $P\left(M^{2}\right)$. That is $\forall r \in R / r \subset M X M$ being $r=\left\{\left(x_{i}, y_{j}\right) \in M \times M / x_{i}, y_{j} \in M\right\}$

The simple empty system-linkage is defined by $\varnothing \equiv(\varnothing, \varnothing)$. Impure system-linkage, as a semiotic system, will be closed if the Subject dispenses with external environment to it and open if it does not do so.

Definition 25: An impure system-linkage defined within an impure object set $M$ is a simple system $S=(M, R)$ or a finite union of simple systems-linkage $\Sigma=\cup_{i=1}^{n_{i}} \Sigma_{i}$ such that $\Sigma_{i}$ are simple systems. This shall be denoted as $\Sigma \equiv(M, R)$ such that $R \subset$ $P\left(\cup_{\text {finite }} M^{2}\right)$.

Note 6: An impure system-linkage shall be open if the Subject recognises the existence of an external environment to it.

Definition 26: The variable is the p-significance of an absolute being or of some of their specific attributes.

Let $\mathrm{M}$ be an impure object set formed by p-significances of absolute beings or their attributes. So that

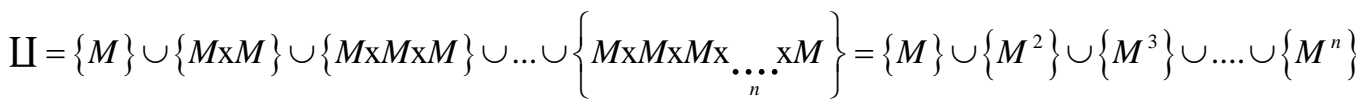

$$
\begin{aligned}
& \text { If } \operatorname{Card} M=m \text { then Card } \amalg=m+m^{2}+m^{3}+\ldots+m^{n}=\frac{m\left(m^{n}-1\right)}{m-1}
\end{aligned}
$$

Definition 27: A Deontical system is an organization of knowledge on the part of the subject $S$ that fulfils the conditions of hypothesis 5 and 7 and the following ones:

a) Other subjects (human beings) are elements of the system.

b) Some existing relations between elements have Deontic modalities.

c) A purpose (purposes) exists.

Hypothesis 10: We considered the concept of Necessity according to the context "absolute obligation". Here, Necessity no longer refers to a property of parts of speech, but to the property added to the real existence of a cognoscible being. The 
necessity of human acts and in as much as these have to be ontically possible and contingent, will be a gnoseolgical property affecting the intellectual ordering of phenomena but not such phenomena themselves. It cannot disobey natural laws (theorems). Nevertheless, in any case, it can be controlled by means of other, natural laws. Normative laws (norms, not theorems) estimate, of necessity, the possibility of a breach. This is its necessity. "Normative Law" and " Natural Law" are not analogues, but syntagmas that include an ambiguous concept: nonanalogues that, with much concession, allow us to interpret metaphorically.

Consequence 18: All systems in whose relations exist Deontic modalities will be put under relations with alethical modalities. That is to say, all systems whose structure is formed by norms also will have a necessary structure of theorems.

All in accordance with Nescolarde-Selva, 2010; Nescolarde-Selva, et al 2012, Nescolarde-Selva and Usó-Domènech, 2012; Usó-Domènech and Nescolarde-Selva, 2012.

A Deontic System will exclusively have in account spheres two and four, in subspheres b, c and d with respect to the system and sphere five with respect to the Subject S. We must, consider the following considerations:

1) Entropy: in spheres four and five, the second law of the thermodynamics is not verified in an exact way. Processes have negative entropy (negentropy). Molar human activity has a strong antientropic component and the same happens with the sphere of inner life.

2) Purpose: In spheres four and five the presence of a special feature is observable : purpose. In sphere two, the state of a system in present time determines what the state will be at a later time. In the sensorial spheres, causality is the present state of things and nothing else. The result of action has no effect on the action that is carried out because of the way things are in the present. In the sphere of molar conduct the result of an action determines partly what happens. As Leibniz says: The spirits are build in accordance with the laws of final causes; the bodies are build in accordance with the laws of efficient causes.

3) Time: Time is not Newtonian time that flows everywhere in a uniform and inexorable way in one direction. This is objective time. Molar conduct comes determined, partly, by the way in which the individual (or the collectivity) perceives the future. Cultural variations within a same society can produce noticeable differences in the way time is perceived and fits to behaviour (LeShan, 1942). We are talking about subjective, personal or collective time, that firstly depends on the individual, secondly on the culture and even on the social groups within the same culture. However, in subjective time, in those situations in which exactitude is needed, or in those situations in which it is necessary to define periods, clock time, objective time is included. This way objective time is a special case of subjective time. If $\left[t_{0}, t_{n}\right]$ is one objective time interval and $\left[t_{0}{ }^{S}, t_{f}{ }^{S}\right]$ is one subjective time interval of the part of Subject $S$, then for this $\mathrm{S}\left[t_{0}, t_{f}\right] \subseteq\left[t_{0}{ }^{s}, t_{f}{ }^{s}\right]$. 
4) Space: Sphere 2 uses Euclidean space. In sphere four and five it is necessary to distinguish a geographic space and a space of conduct. The geographic space has a stable Euclidean component and a changing component according to the changes produced in the visual and tactile sphere. It can be more or less humid or dry; it can be cultivated fields of trees or routes of communication, etc. The conduct space changes not only with our perception of changes as mentioned in the previous paragraph, but those changes vary with our own conscienceness. Two people who are 10 meters apart in a forest can be or not be the same distance from the trees with respect to their inner experience and to their molar conduct. Two different cultures value different forms of the territory where they are based, its limits, etc. The Euclidean geometric space is a special class of human space. Man perceives the human space that includes the geometric space. So, the Euclidean space is a special case of the personal or subjective space. If $\mathrm{L}$ is one objective space and $\mathrm{L}^{\mathrm{S}}$ is one subjective space of the part of Subject $\mathrm{S}$, then for this $\mathrm{S} L \subseteq L^{S}$.

5) Prediction: In the visual and tactile sphere prediction is mechanical (determinist). Nevertheless, in the sphere of molar conduct (sphere 4), the prediction is probabilistic and relative, never absolute. It is possible to predict that the probability that a situation occurs is greater than another one or that in certain individuals the probability that takes place is greater than in others. After an event or an experience is produced it can be that this event or this experience was certain and inevitable. Before taking place, it is not generally possible to predict this event.

6) Language: In sphere 2 (visual and tactile) daily natural language generally is useful and adapted, although there are relations in which mathematical language is needed to express them. The same happens in the sphere of molar conduct. In this sphere the mathematical language is generally probabilistic and the language of modal logic is used. In sphere 5, the inner life, it is not possible to use everyday language, so metaphors are generally used. No pertinent language for mental events has been developed and there is no possibility of carrying out measurements to quantify the data.

7) Variation: The behaviour of $S$ and the elements of $\Gamma$ are not a constant. The tried "human nature" is not the same one in all parts and all times. A immutable and inexorable "human nature" does not exist.

If we denoted as DS a system with Deontic relational structure and we denoted DS a system with alethic relational structure, then $D A \subset D S$. That is to say, nobody in a Deontic system is put under the necessity (understood as absolute obligation) of the theorems or natural laws, people may still ignore the component human beings of this system its existence or may interpret them according to their own belief system.

\section{REFLEXIONS}

Generally, the construction of mathematical models has two distinct phases:

1) A metamodel or formal model, which are addressed specific problems of reality to be modeled. 
2) An operational model (statistical, ordinary, partial, stochastic differential equations, etc.)

By analogy, the first phase corresponds to the plan of a project and the second to completing it. But generally, the modeler did not stop to think what lies behind what is modeled. It's like the engineer who applies physical laws but does not stop to think about what are the causes and reasons for these laws. Behind the model remains a theory, and even a metatheory, not only mathematics (in the end, mathematics is not just a language) but logic, and ultimately, linguistics, indeed it is through language that we apprehend those parts of reality that with our structure we are allowed to know. It is important not to try to reduce systems theory to an empirical approach. It is for this reason that the authors have dared to formulate a hypothesis about something that we considered necessary: a philosophy of systems.

The definition of the concept of an s-impure set as a set of perceptual beliefs or denotative significances (relative beings) of material and/or energetic real objects (absolute beings) is important in approaching Deontic Systems. But not only the subject $\mathrm{S}$ perceives the objects $\mathrm{O}$ as significances, according to what we have exposed in the above paragraphs, one perceives the existing relations between these significances or, in some cases, one infers them. In this paper we approach the structure of the system from the synchronous point of view. This is the reason for this first approach to this class of systems. The study of these relations, conceived not as a singular relation between singular objects, but as sheaves of relations in both directions and forming relational freeways, will be studied in following papers.

\section{REFERENCES}

Agazzi, E. Some Philosophical Implications of Gödel's Theorem. In: Kurt Gödel Actes du Colloque, Neuchâtel, 13-14 juin 1991. (Ed. Denis Miévill). Travaux de Logique, 7. 129-159. 1992.

Beaugrande, R.A. de y W.U. Dressler. 1981. Einführung in die Textlinguistik. Spanihs Trad., Introducción a la lingüística del texto. Barcelona: Ariel, 1997.

Booth, R. Pre-ents, Ents and Generalised rational consequence. A thesis submitted to the University of Manchester for the degree of Doctor of Philosophy in the Faculty of Science. November 2002.

Borhek, J.T. and Curtis, R.F. A Ssociology of Belief. Robert E. Krieger Publishing Company. Malabar. Florida. 1983.

Chandler, D. Semiótica para principiantes. Ediciones Abya-Yala. Quito. Ecuador. 1998. (In Spanish).

Eco, U. El Signo. Editorial Labor. Barcelona, 193, 1976. (In Spanish).

Field, H. Science without Numbers: a Defense of Nomilanism. Princeton University Press. Pricenton. 1980.

Field, H. Realism, Mathematics and Modality. Basil Blackwell. Oxford. 1989. 
Gershenson. C. Comments to Neutrosophy. Proceedings of the First International Conference on Neutrosophy, Neutrosophic Logic, Set, Probability and Statistics, University of New Mexico, Gallup, December 1-3, 2001.

Halpern, M. A guide to modal logics of knowledge and belief. Procs IJCAI, 480-496. 1985.

LeShan, L. and Margenau, H. Einstein's Space and Van Gogh's Sky. MacMillan Publ. Co. Inc. New York. 1982.

Lloret-Climent, M., Usó-Doménech, J.L., B.C. Patten, F. Vives-Maciá. Causality in HSemiotic Systems of Ecosystems. Routes and Tours. International Journal of General Systems. 31(2), 119-130. 2002.

MacCallum, D. Conclusive reasons that we perceive sets. International Studies in the Philosophy of Science. Vol 14, No. 1, 26-42. 2000.

Maddy, P. Realism in Mathematics. Clarendon Press. Oxford. 1990.

Maddy, P. Set theoretic naturalism. Journal of Symbolic Logic, 61. 490-514. 1996.

Meinong, A. Über Gegenstandtheorie. Leipzig. J.A. Barth. 1960 [1904]. (In German).

Nescolarde-Selva, J. A Systemic Vision of Belief Systems and Ideologies. Doctoral Thesis. Universidad de Alicante. Alicante. Spain. 2010.

Nescolarde-Selva, J., Vives-Macía, F., Usó-Domènech, J.L., Berend, D. An introduction to Alysidal Algebra (I). Kybernetes. 41(1/2). 21-34. 2012ª .

Nescolarde-Selva, J., Vives-Macía, F., Usó-Domènech, J.L., Berend, D. An introduction to Alysidal Algebra (II). Kybernetes.41(5/6). 780-793. 2012 .

Nescolarde-Selva, J., Usó-Domènech, J.L., An introduction to Alysidal Algebra (III). Kybernetes. 41(10). 1638-1649. 2012.

Nescolarde-Selva, J., Usó-Domènech, J.L., 2013. Semiotic vision of ideologies. Foundations of Science. (In press).

Patten, B.C. Systems Approach to the concept of Environment. Ohio J. Sci., 78(4), 206222. 1978.

Patten, B.C. Environs: Relativistic Elementary Particles for Ecology. The American Naturalist, 119, 179-219. 1982.

Peirce, C. S. Collected Papers of Charles Sanders Peirce, vols. 1-8, C. Hartshorne, P. Weiss y A. W. Burks (eds.). Cambridge, MA: Harvard University Press. 1931-1958.

Quine, W.V.O. Epistemology naturalised. In: Ontological Relativity. Columbia University. New York. 1969. 
Sastre-Vazquez., P., J.L. Usó-Domènech, Y. Villacampa, J. Mateu and P. Salvador. Statistical Linguistic Laws in Ecological Models. Cybernetics and systems : An international Journal. Vol 30(8). 697-724. 1999.

Saussure, Ferninand de. Curso de lingüística general. Barcelona. Planeta, 1984. (In Spanish).

Usó-Domènech, J.L. and Villacampa, Y. Semantics of Complex Structural Systems: Presentation and Representation. A synchronic vision of language L(MT). Int. Journal of General Systems, 30(4), 479-501. 2001.

Usó-Domènech, J.L., J. Mateu, B.C. Patten. Mathematical Approach to the concept of Environment: Open systems and processes. Int. Journal of General Systems,. 31(3), 213-223. 2002.

Usó-Domènech, J.L., M. Lloret-Climent, F. Vives-Maciá, B.C. Patten, and P. SastreVazquez. Epistemological and Mathematical Considerations on the Structure of $\mathrm{H}$ semiotic Systems. Cybernetics and Systems. An international journal. 33(5), 507-535. 2002.

Usó-Domènech, J.L., G. Stübing, J. López Vila, and P. Sastre Vázquez. Comportamiento de Arbustos Pirófitos en el Paraje Natural Desert de les Palmes.(Prologue by B.C. Patten) Edita Fundación Dávalos-Fletcher. Castellón de la Plana. 2002. (In Spanish).

Usó-Domènech, J.L., J. Mateu. Teoría del Medio Ambiente: Modelización. Publicaciones de la Universitat Jaume I. Colección Medio Ambiente. Vol. 3. 2004. (In Spanish).

Usó-Domènech, J.L. and Nescolarde-Selva, J. Mathematics and Semiotical Theory of Ideological Systems. Lambert Academic Publishing. Saarbruken. Germany. 2012.

Villacampa, Y., Usó-Domènech, J.L., Mateu, J. Vives, F. and Sastre, P.. Generative and Recognoscitive Grammars in Ecological Models. Ecological Modelling. 117, 315-332. 1999.

Villacampa-Esteve, Y., Usó-Domènech, J.L., Castro-Lopez-M, A. and P. SastreVazquez. A Text Theory of Ecological Models. Cybernetics and systems: An International Journal. Vol. 30(7). 587-607. 1999.

Wittgenstein, L. Tractatus Logico-Philosophicus. Routledge\&Kegan Paul. London. 1972. 